\title{
Patterns of bacteria-host associations suggest different ecological strategies between two reef building cold-water coral species
}

\author{
Meistertzheim Anne-Leila ${ }^{1,2}$, Lartaud Franck ${ }^{1,{ }^{*}}$, Arnaud-Haond Sophie ${ }^{3,4}$, Kalenitchenko Dimitri ${ }^{1}$, \\ Bessalam Manon ${ }^{1}$, Le Bris Nadine ${ }^{1}$, Galand Pierre ${ }^{1}$
}

${ }^{1}$ Sorbonne Universités, UPMC Univ Paris 06, CNRS, Laboratoire d'Ecogéochimie des Environnements Benthiques (LECOB), Observatoire Océanologique, 66650, Banyuls sur Mer, France

${ }^{2}$ Centre de Recherches Insulaires et Observatoire de I'Environnement de Polynésie Française, USR

3278 CNRS/EPHE/UPVD, Laboratoire d'Excellence "CORAIL", Université de Perpignan, 66860

Perpignan Cedex, France

${ }^{3}$ Ifremer, Unité Etude des Ecosystèmes Profonds - DEEP, BP 7029280 Plouzané, France

${ }^{4}$ Ifremer, MARBEC - Marine Biodiversity Exploitation and Conservation- Bd Jean Monet 34200 Sète, France

* Corresponding author : Franck Lartaud, Tel.: +334 301924 52; fax: +334 688873 95. ; email

address : franck.lartaud@obs-banyuls.fr

\begin{abstract}
:
Cold-water corals (CWC) are main ecosystem engineers of the deep sea, and their reefs constitute hotspots of biodiversity. However, their ecology remains poorly understood, particularly, the nature of the holobiont formed by corals with their associated bacterial communities. Here, we analysed Madrepora oculata and Lophelia pertusa samples, collected from one location in a Mediterranean canyon in two different seasons (autumn and spring), in order to test for species specificity and temporal stability of the host-bacteria associations. The $16 \mathrm{~S}$ rRNA sequencing revealed host-specific patterns of bacterial communities associated with $L$. pertusa and M. oculata, both in terms of community composition and diversity. All analyzed $M$. oculata polyps exhibited temporally and spatially similar bacterial communities dominated by haplotypes homologous to the known cnidarians-associated genus Endozoicomonas. In contrast, the bacterial communities associated with $L$. pertusa varied among polyps from the same colony, as well as among distinct colonies and between seasons. While the resilient consortium formed by $M$. oculata and its bacterial community fit the definition of holobiont, the versatility of the $L$. pertusa microbiome suggests that this association is more influenced by the environmental conditions or nutritional status. Our results thus highlight distinct host/microbes association strategies for these two closely related Scleractinians sharing the same habitat, suggesting distinct sensitivity to environmental change.
\end{abstract}




\section{Highlights}

- We examine the bacterial communities of two reef-building cold-water coral species from Mediterranean Sea The 16S rRNA sequencing revealed host-specific patterns of bacterial communities both in terms of community composition and diversity - Our results highlight distinct host/microbes association strategies for these two closely related Scleractinians sharing the same habitat, suggesting distinct sensitivity to environmental change.

Keywords : Deep-sea corals, Madrepora oculata, Lophelia pertusa, bacterial communities, bacterial ecology, Mediterranean Sea 


\section{Introduction}

The cold-water scleractinian corals (CWC) are main ecosystem engineers of the deep sea (Roberts et al., 2006). They form reef structures that provide niches and nursery grounds for a variety of species, including commercial and patrimonial species, which make these reefs hotspots of biodiversity at bathyal depth (Roberts et al., 2006). Deep water corals are restricted to cold temperatures $\left(4-14^{\circ} \mathrm{C}\right)$ (Freiwald et al., 2004); nevertheless, they are able to colonize diverse environments from continental shelves, including in submarine canyons, or oceanic features like seamounts to mid-oceanic ridges. Despite the absence of photosynthetic symbiotic zooxanthellae, $\mathrm{CWC}$ are able to build reef structures equivalent to those found in tropical shallow-water environments (Freiwald et al., 2004). However, their growth rates are lower than for most shallow-water coral species (Brooke and Young, 2009; Lartaud et al., 2013; Orejas et al., 2011). Consequently, CWC structures are particularly vulnerable to direct human-induced activities (trawling, oil and gas exploitation, waste discharge), while they are also expected to be sensitive to climate change disturbances such as warming, acidification and deoxygenation (Levin and Le Bris, 2015). Likewise, the destruction of coral habitats results in inestimable losses for juveniles of commercially exploited species (Armstrong et al., 2014). Due to the constraints in accessing deep-sea habitats and the relatively recent efforts to study their ecology, there is a lack of understanding of the processes that underlies their resilience capacity to direct disturbance or environmental changes. This understanding is crucial not only to protect the corals but also to preserve the large number of associated species.

Among the 10 species of reef-building scleractinian CWC described (Freiwald and Roberts, 2005), Lophelia pertusa and Madrepora oculata are the most common and 
occur frequently together in deep waters. Historically, L. pertusa was thought to dominate reef frameworks and, the more fragile $M$. oculata to form associated secondary reefs (Freiwald et al., 2002). However, their dominance pattern can alternate depending on geographical location (e.g., canyons of the Bay of Biscay and Mediterranean Sea; (Arnaud-Haond et al., 2015; Freiwald et al., 2009)). The key factors driving the respective abundance of these species could relies on distinct life strategies for $L$. pertusa and M. oculata (i.e., reproduction (Waller and Tyler, 2005)) or to different energy acquisition pathways as suggested by different growth patterns for individuals sharing the same in situ habitat (Lartaud et al., 2014).

Strong species-specific associations between coral and bacterial communities have been shown for tropical corals (Rohwer et al., 2002), which could be related to coral health (Reshef et al., 2006; Rosenberg et al., 2007). However, compared to tropical corals, research on CWC microbiomes is recent and still scarce. Recently, a symbiotic relationship was revealed between CWC and bacterial communities (Middelburg et al., 2015). Molecular survey have showed that living L. pertusa sampled at different locations harbored active bacterial communities (Yakimov et al., 2006) that were different from the surrounding sediments and water as well from dead coral branches (Neulinger et al., 2008; Schöttner et al., 2012, 2009; Yakimov et al., 2006). Similar results were reported for M. oculata from the North Atlantic Ocean (Hansson et al., 2009; Schöttner et al., 2012). However, the role of these microbes in the host metabolism and health is still unknown. Different bacteria likely have multiple roles in different communities and different parts of the corals. Bacteria observed on the tentacle ectoderm were different from the ones seen on the endoderm of the gastral cavity (Neulinger et al., 
2009). Skeleton and mucus bacteria communities appeared different (Schöttner et al., 2012,2009 ) as well as those communities associated with mucus and polyps (Hansson et al., 2009). Interestingly, distinct bacterial communities were also observed between different color phenotypes of $L$. pertusa (Neulinger et al., 2008) or depending on the position of samples inside the reef (Schöttner et al., 2012). The large disparity in $L$. pertusa bacterial community composition across these studies and within colonies challenges the view of a specific bacteria-host association, even though the differences between L. pertusa and M. oculata bacteria (Hansson et al., 2009; Schöttner et al., 2012) suggest a species-specific association, similar to the one observed in tropical corals (Carlos et al., 2013). Because all the studies performed to date have relied on fingerprinting techniques (Schöttner et al., 2012, 2009) or on a limited number of cloned sequences (Hansson et al., 2009; Kellogg et al., 2009; Neulinger et al., 2008), the identity of potential coral-specific bacteria remains poorly resolved. In addition, M. oculataassociated bacteria have rarely been described in the Mediterranean Sea (Yakimov et al., 2006), where CWC grow at their upper temperature limit.

The main goal of this study was to test whether two different CWC species, $L$. pertusa and M. oculata, harbor species-specific bacterial communities while thriving in a single assemblage, and if this association was temporally variable. We reduced the possible sources of environmental variations by targeting colonies at a single location in the canyon Lacaze-Duthiers, a submarine canyon in the Gulf of Lion (northwestern Mediterranean Sea), characterized by extreme hydrodynamic events in winter transporting high fluxes of particulate material across the canyon (Canals et al., 2006). Each coral colony was identified by microsatellite genotyping and the bacterial 
communities were described in detail by pyrosequencing the 16S rRNA gene. Likewise, we assessed the temporal variability of the coral-bacteria association from polyps tissue of colonies sampled during two different times of the year.

\section{Materials and methods}

\section{Sampling and DNA extraction}

Sampling was conducted using an underwater Remotely Operated Vehicle (ROV Super Achille) on the R/V Minibex Vessel (COMEX S.A.; Figure 1-A). The operations were conducted during two cruises to the Lacaze-Duthiers submarine canyon, off the coast of Banyuls sur Mer in the northwestern Mediterranean Sea $\left(42^{\circ} 32.720\right.$ N; $03^{\circ} 25.260$ W) in November 2010 and May 2011 (at $\sim 520 \mathrm{~m}$ depth). During each cruise, healthy looking coral fragments were randomly collected from 4 colonies of M. oculata and 5 colonies of L. pertusa growing on a small area $(80 \times 30 \mathrm{~m}$, Figure 1-B and C) located at the base of the western flank of the canyon. In particular, two colonies of M. oculata and L. pertusa growing together on the same substrate were sampled (M3 and L4). The colony fragments were collected sequentially with a net held by the gripper of the ROV and placed in separate polypropylene boxes, closed in situ to maintain the ambient bottom water temperature $\left(\sim 13^{\circ} \mathrm{C}\right)$ during the transport to the surface, and avoid cross contamination between samples as well as through the water column. On board, the CWC were dissected with sterilized instruments and gloves. The polyps corresponding to the basal and apical parts (separated by more than four polyps) of an intact fragment (Figure 1-D) were rapidly fixed separately in ethanol. An orange colony of $L$. pertusa was also 
sampled during the second cruise to investigate the relationship between the colors of the polyps (classically white in this area) and the associated bacterial communities.

In the laboratory, the coral fragments were removed from ethanol, cut in two parts, and the polyp tissues were dissected under a binocular microscope. The DNA was extracted from the polyps with the CTAB method (Doyle and Doyle, 1987). Then, the DNA concentrations were measured by spectrophotometry (Nanodrop ND-1000, Thermo Fisher scientific Inc., MA, USA), and the quality was assessed by electrophoresis migration on a $1 \%$ agarose gel.

\section{Microsatellite genotyping}

The presence of clones in colony-replicated samples and the presence of different colonies within our samples was verified using 8 polymorphic microsatellite loci: $\mathrm{c} 016$, g028, g025, g016, C7 and C6 for M. oculata and D3, C44, A105, C126, C91, C61, C120, C142 and A5 for L. pertusa as previously described (Becheler et al., 2016). PCR was used to amplify the microsatellites loci, and the amplified products were diluted in formamide that contained the GENESCAN-350 (ROX; Applied Biosystem Ltd, Foster city, CA, USA) size standard. The size polymorphisms were screened using an ABI Prism 3130 DNA sequencer (Applied Biosystem). The DNA fragments were analyzed using the Genemapper software version 4.0 (Applied Biosystem). The clones present in the different samples were identified using Genclone 2.1 (Arnaud-Haond and Belkhir, 2007).

Sequencing of $16 \mathrm{~S}$ rRNA bacterial genes 
The V3 region of the bacterial 16S rRNA genes were amplified using the 27F AGRGTTTGATCMTGGCTCAG (Lane, 1995) and 519R GTNTTACNGCGGCKGCTG primers (Turner et al., 1999) with a single step and 28 cycles of polymerase chain reaction (PCR) using the HotStarTaq Plus Master Mix Kit (Qiagen, Valencia, CA). The following PCR conditions were used: $94^{\circ} \mathrm{C}$ for $3 \mathrm{~min}$, followed by 28 cycles of $94^{\circ} \mathrm{C}$ for $30 \mathrm{~s}, 53^{\circ} \mathrm{C}$ for $40 \mathrm{~s}$ and $72^{\circ} \mathrm{C}$ for $1 \mathrm{~min}$, after which a final elongation step at $72^{\circ} \mathrm{C}$ for 5 min was performed. Following the PCR, all the amplicon products from the different samples were mixed in equal concentrations and purified using Agencourt Ampure beads (Agencourt Bioscience Corporation, MA, USA). Pyrosequencing was performed with a Roche 454 FLX using commercially prepared Titanium reagents (Research and Testing Laboratory, Lubbock, TX).

\section{Sequence data analyses}

First, the quality of the sequences was controlled by removing all the reads that had a mismatch with the 16S rRNA primers, contained ambiguous nucleotides $(\mathrm{N})$ or were $<$ $300 \mathrm{bp}$ long beyond the forward primer. A stringent quality trimming criteria was applied to remove reads that had $\geq 10 \%$ of bases with Phred values $<27$. This procedure is recommended to ensure that when clustering at $97 \%$, the influence of erroneous reads is minimized (Huse et al., 2010; Kunin et al., 2010). The sequences were then de-replicated and clustered at a 97\% threshold using UCLUST (Edgar, 2010) for de novo OTU picking. The sequences from each operational taxonomic unit (OTU) were classified by comparing them with those from the Greengenes v.2011 database (DeSantis et al., 2006). The read quality filtering and length trimming, data set partitioning based on barcodes, 
de-replication, clustering at $97 \%$ sequence identity and taxonomic classification were performed with PyroTagger (Kunin and Hugenholtz, 2010). Putatively chimeric sequences were identified as sequences having a best Blast alignment $<90 \%$ of the trimmed read length to the reference database, $>90 \%$ sequence identity to the best Blast match and OTU size $\leq 2$.

To compare the bacterial communities in the diversity analysis, all the samples were randomly re-sampled to match the size of the sample containing the fewest sequences $(n=446)$. The Shannon diversity index $\left(H^{\prime},(S h a n n o n, 1948)\right)$, the dominance index $(D=1$-Simpson diversity index (Simpson, 1949)) and a cluster analysis were conducted using the PAST software on the re-sampled dataset (Hammer et al., 2001).

Phylogenetic tree, network analysis and statistics

A phylogenetic tree was constructed from the most relevant OTUs ( $>5 \%$ of the sequences in all the dataset). All the sequences were deposited in the GenBank under Bioproject PRJNA296678 as well as by accession subnumber (SRP064006). The alignment and phylogenic analyses were performed with MEGA6 (Tamura et al., 2013) by including representative sequences from each OTU together with their best match from GenBank. The phylogenetic tree was based on a maximum likelihood calculation according to the generalized time-reversible model of nucleotide substitution with invariant sites and gamma distribution. The robustness of the inferred tree topology was evaluated by 1,000 bootstrap repetitions.

The associations between bacterial OTUs were characterized through MINE statistics by computing the maximal information coefficient (MIC) between each pair of 
OTUs (Reshef et al., 2011). The MIC captures associations between data and provides a score that represents the strength of the relationship between data pairs. A matrix with MIC values $>0.3$ was used with Cytoscape 3.1.1 to visualize the network of associations (Smoot et al., 2011). In these visualizations, the bacterial OTUs are represented as nodes connected by lines; the size of the nodes was proportional to the number of sequences, and the thickness of the lines was proportional to the MIC values. The force-directed layout was edge-weighted by the MIC values. The subnetworks of OTUs were defined with the HC-PIN hierarchical clustering algorithm (Wang et al., 2011). The OTUs were defined as species-specific when their representative sequences were found, at least, in all the duplicate samples of one species and not in the samples of the other species.

An analysis of similarity (ANOSIM) statistics was used to verify the significance of the dendrogram clustering by testing the hypothesis that bacterial communities from the same cluster were more similar in composition to each other than to communities in different clusters. A t-test was used to verify whether the differences in community diversity were significant, the dataset being parametric and the samples independent.

\section{Results}

\section{Host microsatellite genotyping}

The presence of genetically different colonies in our samples and the presence of clonal polyps within the basal and apical replicate samples of each branch were verified by microsatellite genotyping. In M. oculata and L. pertusa, the number of alleles per locus ranged from 2 to 6 (mean $3.8 \pm 0.4$ and $5.1 \pm 0.2$, respectively). All the sampled colonies were genetically different from each other on the basis of at least 7 microsatellite loci. 
The basal and apical replicates corresponded to similar genotypes. The fragments of orange $L$. pertusa did not have a particular genetic signature compared to the white $L$. pertusa colonies.

\section{Alpha diversity}

A total of 60,188 bacterial $16 \mathrm{~S}$ rRNA gene sequences remained from the coral samples after removing the poor quality reads, and a total of 1,110 OTUs were identified at a $97 \%$ sequence similarity cutoff. The Shannon diversity index (H') was significantly lower in M. oculata compared to L. pertusa ( $t$-test, $p=0.04$; Table 1$)$. It varied from 0.0 to 1.4 in M. oculata (mean value of $0.8 \pm 0.6$ ) and from 0.4 to 2.7 in L. pertusa (mean $1.5 \pm 1.0$ ). The Simpson's D dominance index ranged from 0.4 to 1 for M. oculata (mean value 0.7 $\pm 0.2)$ and from 0.1 to 0.8 for $L$. pertusa $(0.4 \pm 0.3)$. The dominance index D was significantly higher in M. oculata compared to L. pertusa ( $t$-test, $p=0.03$ ).

\section{Beta diversity}

A comparison of the bacterial communities was conducted using the Bray-Curtis similarity index, and cluster analysis separated the coral samples into two main groups (Figure 2) that corresponded to the two host species. The bacterial community composition of M. oculata was significantly different from that of L. pertusa (ANOSIM, $\mathrm{p}<0.05$ ). Two L. pertusa communities (L2-A and B) were, however, separated from the other colonies of this species. For M. oculata, the similarity among bacterial communities was relatively high ( $>60 \%$ similarity). The half of duplicate samples, i.e., the tissue within the apex and basal polyps of a single branch, grouped together for M. oculata. No 
difference in community composition was detected between the two sampling dates (Figure 2; ANOSIM, $\mathrm{p}>0.05$ ). The clustering pattern for L. pertusa was different. Several communities were different from each other with similarity values as low as $4 \%$. Although all the duplicate samples grouped together, we observed large differences in the community composition between polyps from the same branch and between different colonies (Figure 2). For L. pertusa, there was a specific temporal difference: all the samples from the spring 2011 grouped together and were separated from those from the autumn 2010 samples.

\section{Bacterial community composition}

All the M. oculata bacterial communities were dominated by OTUs belonging to the class Gammaproteobacteria, which represented $74-99 \%$ of the sequences (Figure 3). The singularity of the M1-A, M1-B and M3-B samples observed in the cluster analysis was due to a higher proportion of Gammaproteobacteria sequences in the bacterial community (96-99\%). Other relevant OTUs belonged to Bacteroidetes, present mostly in sample M4 (9-16\%), and Alphaproteobacteria, present in two M. oculata samples (12$16 \%$ of the sequences).

The dissimilarity observed among $L$. pertusa communities corresponded to the presence of different taxa in the different samples (Figure 3). The majority of the Alphaproteobacteria was observed in colony L1 (79 and $92 \%$ of the sequences in the basal and apical duplicates, respectively). The singularity of the L2 colony was illustrated by the presence of Fusobacteria and Bacteroidetes (26-42\% and 31-37\%, respectively). Among the L. pertusa corals, Gammaproteobacteria represented 6-78\% of the sequences, 
with higher proportions in colonies sampled during May 2011, including the orange phenotype. Less relevant bacterial groups, such as Betaproteobacteria and Spirochaetes, were found exclusively in L. pertusa colonies and represented 1 and $2 \%$ of the sequences, respectively.

\section{Coral species-specific bacteria}

An association network was constructed to identify the OTUs that were closely associated with each other. We identified three subnetworks with the HC-PIN hierarchical clustering algorithm (Figure 4). One network contained 9 closely associated OTUs only found in M. oculata. The other subnetwork contained a group of more closely related OTUs found in L. pertusa. A third group of associated OTUs contained those found in both coral species.

The main OTU from the M. oculata subnetwork (LDC-1; Figure 5) dominated all the M. oculata communities and represented $79 \pm 17 \%$ of the sequences in the colonies (range from 55 to $99 \%$ ). The second main OTU was LDC-3 and represented only $5 \pm 6 \%$ of the sequences identified in M. oculata. These two species-specific OTUs belonged to the order Gammaproteobacteria and presented only $96 \%$ of similarity to Endozoicomonas numazuensis (GenBank accession NR11431), a facultative anaerobes that might ferment carbohydrates (Nishijima et al., 2013); Table S1 and Figure 6). The next relevant OTU, LDC-4, contained $4 \pm 6 \%$ of the sequences obtained from M. oculata (Figure 5). The LDC-4 representative sequence had the highest similarity (93\%) to an uncultured Elizabethkingia sp. (DQ917866) that belongs to the Flavobacteriaceae family (Bacteriodetes; Figure 6). Other bacteria specific to M. oculata, previously associated 
with cnidarians (i.e., LDC-2, 6, 8 and 13), were identified with lower sequence abundance (less than 2\%) and belonged to the classes Alphaproteobacteria and Epsilonproteobacteria.

The second cluster was specific to L. pertusa samples and was composed of 15 weakly connected OTUs (Figure 4), which included the LDC-10 OTU found in all the $L$. pertusa samples. The sequence abundance of the LDC-10 OTU ranged from less than 1 to $83 \%$ and represented $31 \pm 32 \%$ of all the $L$. pertusa sequences (Figure 5). This $L$. pertusa-specific OTU was classified as a Gammaproteobacteria with the highest homology (98\%) to a black coral -associated bacteria clone (ctg_CGODA50,(Penn et al., 2006); Table S1, Figure 6). Other OTUs were detected only in Lophelia samples; however, they were not present in all the colonies. For example, the OTU LDC-9 represented $19 \pm 38 \%$ of the species sequences and belonged to Alphaproteobacteria (high homology, 97\%) together with an uncultured bacterium (clone 6215-B73) identified in the gorgonian corals from the Aleutian Islands (Gray et al., 2011). However, the LDC-9 was detected with a high proportion only in one L. pertusa colony (between 79 to $92 \%$ of the total sample sequences of L1-A and L1-B, respectively). Interestingly, the OTU LDC-11 was only observed in the orange Lophelia colony (average of 23\%). This OTU showed a high similarity (93\%) with sequences previously associated with cnidarians identified as Alphaproteobacteria (clone P7-G09, (Bayer et al., 2013b)). Twelve other rare OTUs $(<2 \%$ abundance) were observed only in certain $L$. pertusa samples and together represented $15 \%$ of the total species-specific sequences.

Other relevant OTUs in CWC were shared between the two species. LDC-26 represented $8 \pm 16 \%$ of the sequences in $L$. pertusa and $2 \pm 4 \%$ in $M$. oculata. In addition, 
it had the highest similarity (95\%) to zebrafish digestive tract clone aab53e01

(Cetobacterium somerae, Fusobacteria), which has also previously been reported as associated with cnidarians. The LDC- 18 represented $4 \pm 8 \%$ of the $L$. pertusa sequences and $0 \pm 1 \%$ of $M$. oculata and had a high similarity $(90 \%)$ with an uncultured bacterium previously associated with deep seawater (Bacteroidetes).

\section{Host associated bacteria}

We tested whether the bacteria we amplified from coral polyps represented typical hostassociated microbes or if they were similar to bacteria from other environments. We grouped the OTUs representing more than $5 \%$ of the sequences that had the best GenBank match (more than $82 \%$ ) to sequences retrieved from a similar environment (associated to cnidarian, fishes found in the deep sea, in coastal shallow seawaters or from terrestrial origin, Figure 5). For M. oculata, $97 \%$ of the bacterial sequences were similar to those previously associated to cnidarians, while that was the case for only $67 \%$ of the L. pertusa sequences. The OTUs associated with deep sea environments (hydrothermal vents and surface sediments) represented less than $1 \%$ of the sequences in M. oculata and $3 \%$ in L. pertusa. In addition, L. pertusa had $14 \%$ of bacterial sequences that matched OTUs associated with samples from shallow marine environments, compared to $1 \%$ for M. oculata. Among the remaining sequences, 9 and $2 \%$ presented high homology with microbes associated with fishes in L. pertusa and M. oculata, respectively. Finally, 3\% of sequences homologous to lineages from terrestrial samples were identified only in L. pertusa (Figure 5). 
Finally, the 14 non species-specific OTUs matched OTUs previously found to be associated with samples from marine environments and fishes.

\section{Phylogenetic analyses}

No specific phylogenetic signal was observed between the bacterial communities of M. oculata and L. pertusa (Figure 6). However, among the Gammaproteobacteria, the species-specific OTUs were grouped according to the CWC species they originated from. Ten $L$. pertusa OTUs clustered together with LDC-10 and were separated from the main OTUs identified in M. oculata (LDC-1 and LDC-3). These M. oculata Endozoicomonas phylotypes were $95 \%$ similar to published sequences and grouped together in the phylogenetic tree (Figure 6). In contrast, the Alphaproteobacteria OTUs from both species clustered together in the phylogenetic tree.

\section{Discussion}

This first temporal characterization of bacterial communities associated with both $L$. pertusa and M. oculata in the Mediterranean Sea challenges previous results that showed intra- (Hansson et al., 2009) and inter- (Hansson et al., 2009; Schöttner et al., 2012) colony versatility of bacterial communities in M. oculata versus the spatial stability of $L$. pertusa (Schöttner et al., 2012). Indeed, our results show a low diversity in the temporally stable and species-specific communities associated with M. oculata. Instead, those bacterial communities associated with $L$. pertusa were more diverse and variable in space and time as well as possibly more susceptible to environmental variations. Our data support, however, previous findings based on DGGE (Hansson et al., 2009) and ARISA 
(Schöttner et al., 2012) on the Northern Atlantic reefs that showed species-specific communities for M. oculata.

Our study on the corals from the northwestern Mediterranean deep-sea shows that $L$. pertusa and M. oculata collected at the same time at the same location had different associated bacteria, as observed for other CWCs (e.g. Anthothela sp. (Lawler et al., 2016)). The difference was observed in community composition, diversity of the community and specificity of the association. Overall, our results indicate that CWC bacterial communities are first structured by the host species and, thus, demonstrate that the earlier findings based on DGGE fingerprinting from the North Atlantic Ocean (Hansson et al., 2009) and based on ARISA from the Norwegian Sea (Schöttner et al., 2012) extend to the Mediterranean Sea. In M. oculata, however, our results showed that species-specific bacterial associations with colonies and polyps remained stable throughout the seasons, which contradicts the few existing data on M. oculata that suggest a within colony variability (Hansson et al., 2009; Schöttner et al., 2012). The stable community we report here might represent true host-associated bacteria because we directly targeted the bacteria from the tissue within the polyp, whereas earlier studies that amplified bacterial sequences from the mucus or from scraping branches could have detected opportunistic bacteria growing on the coral. In contrast, the bacterial communities associated with $L$. pertusa varied within the same sampling area, between polyps from the same colony and between seasons. This result also differs from earlier findings that showed that L. pertusa bacteria communities were more stable than those from M. oculata (Schöttner et al., 2012). However, our large amount of sequencing data 
support the spatial variations reported earlier in L. pertusa (Hansson et al., 2009; Kellogg et al., 2009; Neulinger et al., 2008; Schöttner et al., 2009).

Our observation of the Lacaze-Duthiers submarine canyon probably reflects an essential difference in the microbe-host association strategy of both species. The high variability in the bacteria assemblages of $L$. pertusa compared with the higher specificity of M. oculata could reflect different ecological niches occupied by two species sharing the same habitat. This strategy was suggested for colonies from the European margins (Arnaud-Haond et al., 2015). Schöttner et al. attributed the variations in the bacterial community composition to both stochastic events and deterministic processes (Schöttner et al., 2012). The former corresponds to the random attachment of environmental bacteria to coral surfaces (Ritchie, 2006), and the latter reflects a selective regulation by the coral host (Rohwer and Kelley, 2004) and bacterial interactions with coral tissues (Rypien et al., 2010). For L. pertusa, we suggest that the lack of bacterial community stability in all the spatial scales, from intra to inter colony, might be because the bacterial communities detected in the polyps represent the microbiome of the coral gastrovascular cavity. We can, thus, hypothesize that the composition of the microbiome reflects the diet of the host as observed for other gut microbiomes (David et al., 2014; Miyake et al., 2015). In the hypothesis of a predominantly diet-shaped bacterial community, the stable M. oculata bacterial community might, then, indicate a narrow diet based on specific prey selected by the polyps. Conversely, the variable $L$. pertusa bacteria might reflect an opportunistic coral species that capture different prey depending on the location of the colony and the time of the year. Although both species rely predominantly on a zooplankton-based diet (Kiriakoulakis et al., 2005; Naumann et al., 2015), the enrichment in mono-unsaturated 
fatty acids and $\delta^{15} \mathrm{~N}$ of $L$. pertusa tissues relative to $M$. oculata suggests possible different feeding strategies, different assimilation/storage efficiencies or different metabolisms between the two coral species (Kiriakoulakis et al., 2005).

In addition, in situ growth patterns were shown to differ between the two coral species on a seasonal basis (Lartaud et al., 2014). The winter dense water-cascading regime that characterize the northwestern Mediterranean canyons (Canals et al., 2006) was hypothesized as a potential cause of these changes that affect the growth of M. oculata but not that of $L$. pertusa (Lartaud et al., 2014). The differences in their specific microbiota further support the idea of L. pertusa as a more opportunistic species that is able to adapt its nutritional strategy. Instead, M. oculata growth would be perturbed if its specific prey disappears. Similarly, the thermal tolerance of $L$. pertusa is higher than that of M. oculata, which is highlighted by the decrease in respiration and calcification rate when M. oculata colonies change from 13 to 9 or $6^{\circ} \mathrm{C}$ (Naumann et al., 2014). Alternatively, the bacteria we detected could also represent communities associated with the coral mucus. The mucus of $L$. pertusa and M. oculata have different $\mathrm{C}: \mathrm{N}$ ratios and carbohydrate compositions (Wild et al., 2010, 2008), and M. oculata has an enormous potential for mucus production (Reitner, 2005). This could also lead to differences in the host-bacteria association because the coral mucus plays a significant role in the structuring of beneficial coral-associated microbia (Ritchie, 2006). However, this difference is insufficient to explain the variability of $L$. pertusa communities between two polyps of the same branch, separated by some centimeters.

Bacterial communities associated with M. oculata appeared to be more structured by the host species rather than by the temporal or spatial variability of the environmental 
conditions, which is similar to the behavior of microbes associated with tropical corals (Knowlton and Rohwer, 2003). The M. oculata bacterial communities were dominated by two Endozoicomonas phylotypes that have been named Spongiobacter in earlier CWC studies (Hansson et al., 2009). We propose the use of Endozoicomonas because the previously mentioned Spongiobacter is based on its similarity to a GenBank sequence (AB205011) from a strain that has never been published. Conversely, the isolated Endozoicomonas strain and the genus itself were recently described (Neave et al., 2014; Nishijima et al., 2013; Pike et al., 2013). Endozoicomonas are aerobic or facultatively anaerobic bacteria that can perform carbohydrate fermentation (Neave et al., 2014; Nishijima et al., 2013; Pike et al., 2013) but their role in the host in still unknown.

Our sequences had only $95 \%$ sequence identity to the closest cultivated strain, Endozoicomonas numazuensis. Different phylotypes that belong to the genus Endozoicomonas were previously obtained from several cnidarian taxa, such as tropical coral species (Agostini et al., 2011; Ainsworth et al., 2015; Littman et al., 2009) and gorgonian (Eunicella cavolini, E. verrucosa, Plexaura sp. and E. fusca; (Bayer et al., 2013a; Pike et al., 2013; Ransome et al., 2014) but also from sponges in the Mediterranean Sea (Thiel et al., 2007). As suggested for other CWC(Hansson et al., 2009; Neulinger et al., 2008), we can assume a general class of coral-associated bacteria shared by both shallow- and deep-water corals, with ecological niches filled by different bacterial phylotypes in different host species. However, this close association between Endozoicomonas and coral or gorgonian could depend on the corals' health status (Bourne et al., 2008; Ransome et al., 2014). For example, healthy corals of Acropora millepora harbor high abundance of Endozoicomonas (Spongiobacter; more than 41\%) 
compared to bleached corals (less than 3\%). This last result could also explain the variations in the dominance of these bacteria types observed in Acropora sp. as a function of the sampling sites (Littman et al., 2009). During our sampling, only healthy looking colonies of M. oculata were targeted. We can speculate that the dominance of this genus in M. oculata samples reveals the healthy status of the coral host.

In contrast, the bacterial communities associated with L. pertusa appeared more structured by variable spatial or temporal environmental factors as illustrated by the intersamples, inter-season and inter-habitat differences. However, we identified one speciesspecific microbe that was always associated with L. pertusa polyps, i.e., LCD $10[98 \%$ similarity to black coral clone ctg CGODA50 (Penn et al., 2006)]. It was present in different polyps, colonies, seasons, and colors but with a strong variation in abundance. This microbe has been reported to be associated with black coral in the seamounts of the Gulf of Alaska (Penn et al., 2006).

Interestingly, the bacterial communities observed in L. pertusa and M. oculata sampled in the Mediterranean Sea (at ca. $13^{\circ} \mathrm{C}$ ) were not present in the colonies sampled at ca. $5^{\circ} \mathrm{C}$ in the NE Atlantic Ocean [e.g., Norwegian shelf (Wild et al., 2008), Ireland (Hansson et al., 2009; van Bleijswijk et al., 2015)] nor associated with the same species sampled at ca. $8^{\circ} \mathrm{C}$ in the northern Gulf of Mexico (Galkiewicz et al., 2011; Kellogg et al., 2009). Conversely, the most abundant clones previously associated with CWC were not detected in this study, except for bacteria of the genus Endozoicomonas (van Bleijswijk et al., 2015). For example, L. pertusa-specific mycoplasma-like bacteria, i.e., Mycoplasma spp. (Kellogg et al., 2009; Neulinger et al., 2008; van Bleijswijk et al., 2015) identified through culture-independent methods and other bacteria such as 
Pseudoalteromonas spp., Photobacterium spp., uncultured Achromobacter sp. identified through culture-dependent methods (Galkiewicz et al., 2011) were not found in our sampling. None of the Endozoicomonas identified in M. oculata from our Mediterranean samples were previously identified associated with this species in the Atlantic Ocean (95\% similarity to clone ME19, DQ917863 (Hansson et al., 2009)). However, Endozoicomonas sp. was previously identified in low proportion in mucus of L. pertusa sampled at ca. $8^{\circ} \mathrm{C}$ in the Logachev Mound province in NE Atlantic waters (van Bleijswijk et al., 2015). Accordingly, the coral associated bacterial assemblages could differ between the NE Atlantic Ocean and the Mediterranean Sea because they might have different temperature (and/or salinity) range tolerances. Other bacteria were identified after culturing them at $4{ }^{\circ} \mathrm{C}$ (Galkiewicz et al., 2011), which lead to a methodological bias when compared to bacteria studied using molecular tools, explaining their absence in other studies (Kellogg et al., 2009; Neulinger et al., 2008). This specificity of the bacterial assemblages of the CWC from the Gulf of Lion could be related to local environmental conditions or host genetic specificity and requires further investigation throughout the Atlantic Ocean and the Mediterranean Sea.

Finally, we provide the first in-depth investigation, based on a mass characterization of rRNA 16S lineages, on the species-specific bacterial communities harbored by Mediterranean CWC in different seasons. Specific bacterial associations were identified for the first time, with a high spatial and temporal community stability harbored by $M$. oculata, whereas the microbial pattern of $L$. pertusa appeared more versatile and probably to be more influenced by environmental conditions. This result partially 
contradicts previous findings based on classical methods and suggests different adaptive strategies of two species that share the same habitat. Interestingly, the dominance of the genus Endozoicomonas in M. oculata could also reflect a potential symbiosis between this genus and CWC, as observed in other cnidarians.

\section{References}

Agostini, S., Suzuki, Y., Higuchi, T., Casareto, B.E., Yoshinaga, K., Nakano, Y., Fujimura, H., 2011. Biological and chemical characteristics of the coral gastric cavity. Coral Reefs 31, 147-156. doi:10.1007/s00338-011-0831-6

Ainsworth, T.D., Krause, L., Bridge, T., Torda, G., Raina, J.-B., Zakrzewski, M., Gates, R.D., Padilla-Gamiño, J.L., Spalding, H.L., Smith, C., Woolsey, E.S., Bourne, D.G., Bongaerts, P., Hoegh-Guldberg, O., Leggat, W., 2015. The coral core microbiome identifies rare bacterial taxa as ubiquitous endosymbionts. ISME J. 1-14. doi:10.1038/ismej.2015.39

Armstrong, C.W., Foley, N.S., Kahui, V., Grehan, A., 2014. Cold water coral reef management from an ecosystem service perspective. Mar. Policy 50, 126-134. doi:10.1016/j.marpol.2014.05.016

Arnaud-Haond, S., Belkhir, K., 2007. genclone: a computer program to analyse genotypic data, test for clonality and describe spatial clonal organization. Mol. Ecol. Notes 7, $15-17$.

Arnaud-Haond, S., Van den Beld, I.M.J.M.J., Becheler, R., Orejas, C., Menot, L., Frank, N., Grehan, A., Bourillet, J.F.F., 2015. Two "pillars" of cold-water coral reefs along Atlantic European margins: Prevalent association of Madrepora oculata with Lophelia pertusa, from reef to colony scale. Deep Sea Res. Part II Top. Stud. Ocean. doi:10.1016/j.dsr2.2015.07.013

Bayer, T., Arif, C., Ferrier-Pagès, C., Zoccola, D., Aranda, M., 2013a. Bacteria of the genus Endozoicomonas dominate the microbiome of the Mediterranean gorgonian coral Eunicella cavolini. Mar. Ecol. Prog. Ser. 479, 75-84.

Bayer, T., Neave, M.J., Alsheikh-Hussain, A., Aranda, M., Yum, L.K., Mincer, T., Hughen, K., Apprill, A., Voolstra, C.R., 2013b. The microbiome of the red sea coral Stylophora pistillata is dominated by tissue-associated Endozoicomonas bacteria. Appl. Environ. Microbiol. 79, 4759-4762. doi:10.1128/AEM.00695-13

Becheler, R., Cassone, A.-L., Noel, P., Mouchel, O., Morrison, C.L., Arnaud-Haond, S., 2016. Low incidence of clonality in cold water corals revealed through a standardized protocol adapted to deep sea sampling. Deep Sea Res. Part II Top. 
Stud. Oceanogr. doi:doi:10.1016/j.dsr2.2015.11.013

Bourne, D., Iida, Y., Uthicke, S., Smith-Keune, C., 2008. Changes in coral-associated microbial communities during a bleaching event. ISME J. 2, 350-63. doi:10.1038/ismej.2007.112

Brooke, S., Young, C.M., 2009. In situ measurement of survival and growth of Lophelia pertusa in the northern Gulf of Mexico. Mar Ecol Prog Ser 397, 153-161.

Canals, M., Puig, P., de Madron, X.D., Heussner, S., Palanques, A., Fabres, J., 2006. Flushing submarine canyons. Nature 444, 354-357.

Carlos, C., Torres, T.T., Ottoboni, L.M.M., 2013. Bacterial communities and speciesspecific associations with the mucus of Brazilian coral species. Sci. Rep. 3, 1624. doi:10.1038/srep01624

David, L.A., Maurice, C.F., Carmody, R.N., Gootenberg, D.B., Button, J.E., Wolfe, B.E., Ling, A. V, Devlin, A.S., Varma, Y., Fischbach, M.A., Biddinger, S.B., Dutton, R.J., Turnbaugh, P.J., 2014. Diet rapidly and reproducibly alters the human gut microbiome. Nature 505, 559-563.

DeSantis, T.Z., Hugenholtz, P., Larsen, N., Rojas, M., Brodie, E.L., Keller, K., Huber, T., Dalevi, D., Hu, P., Andersen, G.L., 2006. Greengenes, a Chimera-Checked 16S rRNA Gene Database and Workbench Compatible with ARB. Appl. Environ. Microbiol. 72, 5069-5072. doi:10.1128/AEM.03006-05

Doyle, J.J., Doyle, J.L., 1987. A rapid DNA isolation procedure for small quantities of fresh leaf tissue. Phytochem. Bull. 19, 11-15.

Edgar, R.C., 2010. Search and clustering orders of magnitude faster than BLAST. Bioinformatics 26, 2460-2461. doi:10.1093/bioinformatics/btq461

Freiwald, A., Beuck, L., Rüggeberg, A., Taviani, M., Hebbeln, D., R/V Meteor M70-1, P., 2009. The white coral community in the central Mediterranean Sea revealed by ROV surveys. Oceanography 22, 58-74.

Freiwald, A., Fosså, J.H., Grehan, A., Koslow, T., Roberts, J.M., 2004. Cold-water Coral Reefs. UNEP-WCMC, Cambridge, U.K.

Freiwald, A., Hühnerbach, V., Lindberg, B., Wilson, J., Campbell, J., 2002. The Sula Reef Complex, Norwegian shelf. Facies 47, 179-200. doi:10.1007/BF02667712

Freiwald, A., Roberts, J.M., 2005. Cold-Water Corals and Ecosystems. Springer Berlin Heidelberg, $1241 \mathrm{p}$.

Galkiewicz, J.P., Pratte, Z.A., Gray, M.A., Kellogg, C.A., 2011. Characterization of culturable bacteria isolated from the cold-water coral Lophelia pertusa. FEMS Microbiol. Ecol. 77, 333-346. doi:10.1111/j.1574-6941.2011.01115.x

Gray, M.A., Stone, R.P., Mclaughlin, M.R., Kellogg, C.A., 2011. Microbial consortia of gorgonian corals from the Aleutian islands. FEMS Microbiol. Ecol. 76, 109-120. doi:10.1111/j.1574-6941.2010.01033.x

Hammer, Ø., Harper, D.A.T., Ryan, P.D., 2001. Past: Paleontological Statistics Software 
Package for education and data analysis. Paleontologia Electronica 4: 1-9.

Hansson, L., Agis, M., Maier, C., Weinbauer, M.G.G., 2009. Community composition of bacteria associated with cold-water coral Madrepora oculata: within and between colony variability. Mar. Ecol. Prog. Ser. 397, 89-102. doi:10.3354/meps08429

Huse, S.M., Welch, D.M., Morrison, H.G., Sogin, M.L., 2010. Ironing out the wrinkles in the rare biosphere through improved OTU clustering. Environ. Microbiol. 12, 18891898. doi:10.1111/j.1462-2920.2010.02193.x

Kellogg, C.A., Lisle, J.T., Galkiewicz, J.P., 2009. Culture-independent characterization of bacterial communities associated with the cold-water coral Lophelia pertusa in the northeastern Gulf of Mexico. Appl. Environ. Microbiol. 75, 2294-2303. doi:10.1128/AEM.02357-08

Kiriakoulakis, K., Fisher, E., Wolff, G., Freiwald, A., Grehan, A., Roberts, J.M., 2005. Lipids and nitrogen isotopes of two deep-water corals from the North-East Atlantic: initial results and implications for their nutrition, in: Freiwald, A., Roberts, J.M. (Eds.), Cold-Water Corals Ecosyst. Springer Berlin Heidelberg, pp. 715-729.

Knowlton, N., Rohwer, F., 2003. Multispecies Microbial Mutualisms on Coral Reefs: The Host as a Habitat. Am. Nat. 162, S51-S62. doi:10.1086/378684

Kunin, V., Engelbrektson, A., Ochman, H., Hugenholtz, P., 2010. Wrinkles in the rare biosphere: pyrosequencing errors can lead to artificial inflation of diversity estimates. Environ. Microbiol. 12, 118-123. doi:10.1111/j.1462-2920.2009.02051.x

Kunin, V., Hugenholtz, P., 2010. PyroTagger: a fast, accurate pipeline for analysis of rRNA amplicon pyrosequence data. Open J. 1.

Lartaud, F., Pareige, S., de Rafelis, M., Feuillassier, L., Bideau, M., Peru, E., De la Vega, E., Nedoncelle, K., Romans, P., Le Bris, N., 2014. Temporal changes in the growth of two Mediterranean cold-water coral species, in situ and in aquaria. Deep. Res. Part II Top. Stud. Oceanogr. 99, 64-70. doi:10.1016/j.dsr2.2013.06.024

Lartaud, F., Pareige, S., de Rafelis, M., Feuillassier, L., Bideau, M., Peru, E., Romans, P., Alcala, F., Le Bris, N., 2013. A new approach for assessing cold-water coral growth in situ using fluorescent calcein staining. Aquat. Living Resour. 26, 187-196. doi:10.1051/alr/2012029

Lawler, S.N., Kellogg, C.A., France, S.C., Clostio, R.W., Brooke, S., Ross, S., 2016. Coral-associated bacterial diversity is conserved across two deep-sea Anthothela species. Front. Microbiol. 7, 458.

Levin, L.A., Le Bris, N., 2015. The deep ocean under climate change. Sci. 350 , 766768. doi:10.1126/science.aad0126

Littman, R.A., Willis, B.L., Pfeffer, C., Bourne, D.G., 2009. Diversities of coralassociated bacteria differ with location, but not species, for three acroporid corals on the Great Barrier Reef. FEMS Microbiol. Ecol. 68, 152-63. doi:10.1111/j.15746941.2009.00666.x

Middelburg, J.J., Mueller, C.E., Veuger, B., Larsson, A.I., Form, A., van Oevelen, D., 
2015. Discovery of symbiotic nitrogen fixation and chemoautotrophy in cold-water corals. Sci. Rep. 5, 17962. doi:10.1038/srep17962

Miyake, S., Ngugi, D.K., Stingl, U., 2015. Diet strongly influences the gut microbiota of surgeonfishes. Mol. Ecol. 24, 656-672. doi:10.1111/mec.13050

Naumann, M., Tolosa, I., Taviani, M., Grover, R., Ferrier-Pagès, C., 2015. Trophic ecology of two cold-water coral species from the Mediterranean Sea revealed by lipid biomarkers and compound-specific isotope analyses. Coral Reefs 1-11. doi:10.1007/s00338-015-1325-8

Naumann, M.S., Orejas, C., Ferrier-Pagès, C., 2014. Species-specific physiological response by the cold-water corals Lophelia pertusa and Madrepora oculata to variations within their natural temperature range. Deep Sea Res. Part II Top. Stud. Oceanogr. 99, 36-41. doi:10.1016/j.dsr2.2013.05.025

Neave, M.J., Michell, C.T., Apprill, A., Voolstra, C.R., 2014. Whole-genome sequences of three symbiotic Endozoicomonas strains. Genome Announc. 2, e00802-14. doi:10.1128/genomeA.00802-14

Neulinger, S.C., Gärtner, A., Järnegren, J., Ludvigsen, M., Lochte, K., Dullo, W.-C., 2009. Tissue-associated "Candidatus Mycoplasma corallicola" and filamentous bacteria on the cold-water coral Lophelia pertusa (Scleractinia). Appl. Environ. Microbiol. 75, 1437-1444. doi:10.1128/aem.01781-08

Neulinger, S.C., Järnegren, J., Ludvigsen, M., Lochte, K., Dullo, W.-C., 2008. Phenotype-specific bacterial communities in the cold-water coral Lophelia pertusa (Scleractinia) and their implications for the coral's nutrition, health, and distribution. Appl. Environ. Microbiol. 74, 7272-7285. doi:10.1128/aem.01777-08

Nishijima, M., Adachi, K., Katsuta, A., Shizuri, Y., Yamasato, K., 2013. Endozoicomonas numazuensis sp. nov., a gammaproteobacterium isolated from marine sponges, and emended description of the genus Endozoicomonas Kurahashi and Yokota 2007. Int. J. Syst. Evol. Microbiol. 63 , 709-714. doi:10.1099/ijs.0.042077-0

Orejas, C., Ferrier-Pagès, C., Reynaud, S., 2011. Long-term growth rates of four Mediterranean cold-water coral species maintained in aquaria. Mar Ecol Prog Ser $429,57-65$.

Penn, K., Wu, D., Eisen, J.A., Ward, N., 2006. Characterization of bacterial communities associated with deep-sea corals on Gulf of Alaska seamounts. Appl. Environ. Microbiol. 72, 1680-1683. doi:10.1128/AEM.72.2.1680-1683.2006

Pike, R.E., Haltli, B., Kerr, R.G., 2013. Description of Endozoicomonas euniceicola sp. nov. and Endozoicomonas gorgoniicola sp. nov., bacteria isolated from the octocorals Eunicea fusca and Plexaura sp., and an emended description of the genus Endozoicomonas. Int. J. Syst. Evol. Microbiol. 63, 4294-4302. doi:10.1099/ijs.0.051490-0

Ransome, E., Rowley, S.J., Thomas, S., Tait, K., Munn, C.B., 2014. Disturbance to conserved bacterial communities in the cold-water gorgonian coral Eunicella 
verrucosa. FEMS Microbiol. Ecol. 90, 404-16. doi:10.1111/1574-6941.12398

Reitner, J., 2005. Calcifying extracellular mucus substances (EMS) of Madrepora oculata - a first geobiological approach, in: Freiwald, A., Roberts, J.M. (Eds.), Cold-Water Corals and Ecosystems. Springer Berlin Heidelberg, pp. 731-744. doi:10.1007/3-540-27673-4_38

Reshef, D.N., Reshef, Y.A., Finucane, H.K., Grossman, S.R., McVean, G., Turnbaugh, P.J., Lander, E.S., Mitzenmacher, M., Sabeti, P.C., 2011. Detecting novel associations in large data sets. Sci. (80-. ). 334, 1518-1524. doi:10.1126/science. 1205438

Reshef, L., Koren, O., Loya, Y., Zilber-Rosenberg, I., Rosenberg, E., 2006. The coral probiotic hypothesis. Environ. Microbiol. 8, 2068-2073.

Ritchie, K.B., 2006. Regulation of microbial populations by coral surface mucus and mucus-associated bacteria. Mar. Ecol. Prog. Ser. 322, 1-14. doi:10.3354/meps322001

Roberts, J.M., Wheeler, A.J., Freiwald, A., 2006. Reefs of the deep: the biology and geology of cold-water coral ecosystems. Science 312, 543-547. doi:10.1126/science. 1119861

Rohwer, F., Kelley, S., 2004. Culture-independent analyses of coral-associated microbes, in: Rosenberg, E., Loya, Y. (Eds.), Coral Health and Disease. Springer Berlin Heidelberg, pp. 265-277. doi:10.1007/978-3-662-06414-6

Rohwer, F., Seguritan, V., Azam, F., Knowlton, N., 2002. Diversity and distribution of coral-associated bacteria. Mar. Ecol. Prog. Ser. 243, 1-10.

Rosenberg, E., Koren, O., Reshef, L., Efrony, R., Zilber-Rosenberg, I., 2007. The role of microorganisms in coral health, disease and evolution. Nat. Rev. Microbiol. 5, 355362.

Rypien, K.L., Ward, J.R., Azam, F., 2010. Antagonistic interactions among coralassociated bacteria. Environ. Microbiol. 12, 28-39. doi:10.1111/j.14622920.2009.02027.x

Schöttner, S., Hoffmann, F., Wild, C., Rapp, H.T., Boetius, A., Ramette, A., 2009. Interand intra-habitat bacterial diversity associated with cold-water corals. ISME J 3, 756-759.

Schöttner, S., Wild, C., Hoffmann, F., Boetius, A., Ramette, A., 2012. Spatial scales of bacterial diversity in cold-water coral reef ecosystems. PLoS One 7, e32093. doi:10.1371/journal.pone.0032093

Shannon, C.E., 1948. A mathematical theory of communication. Bell Syst. Tech. J. 27, 379-423. doi:10.1145/584091.584093

Simpson, E.H., 1949. Measurement of Diversity. Nature 163, 688-688.

Smoot, M.E., Ono, K., Ruscheinski, J., Wang, P.-L., Ideker, T., 2011. Cytoscape 2.8: new features for data integration and network visualization. Bioinformatics 27, 431-432. 
doi:10.1093/bioinformatics/btq675

Tamura, K., Stecher, G., Peterson, D., Filipski, A., Kumar, S., 2013. MEGA6: Molecular Evolutionary Genetics Analysis Version 6.0. Mol. Biol. Evol. 30, 2725-2729. doi:10.1093/molbev/mst197

Thiel, V., Leininger, S., Schmaljohann, R., Brümmer, F., Imhoff, J.F., 2007. Spongespecific bacterial associations of the Mediterranean sponge Chondrilla nucula (Demospongiae, Tetractinomorpha). Microb. Ecol. 54, 101-11. doi:10.1007/s00248006-9177-y

Turner, S., Pryer, K.M., Miao, V.P., Palmer, J.D., 1999. Investigating deep phylogenetic relationships among cyanobacteria and plastids by small subunit rRNA sequence analysis. J. Eukaryot. Microbiol. 46, 327-338. doi:10.1111/j.15507408.1999.tb04612.x

van Bleijswijk, J.D.L., Whalen, C., Duineveld, G.C. a., Lavaleye, M.S.S., Witte, H.J., Mienis, F., 2015. Microbial assemblages on a cold-water coral mound at the SE Rockall Bank (NE Atlantic): interactions with hydrography and topography. Biogeosciences 12, 4483-4496. doi:10.5194/bg-12-4483-2015

Waller, R.G., Tyler, P.A., 2005. The reproductive biology of two deep-water, reefbuilding scleractinians from the NE Atlantic Ocean. Coral Reefs 24, 514-522. doi:10.1007/s00338-005-0501-7

Wang, J., Li, M., Chen, J., Pan, Y., 2011. A fast hierarchical clustering algorithm for functional modules discovery in protein interaction networks. IEEE/ACM Trans. Comput. Biol. Bioinform. 8, 607-20. doi:10.1109/TCBB.2010.75

Wild, C., Mayr, C., Wehrmann, L., 2008. Organic matter release by cold water corals and its implication for fauna-microbe interaction. Mar Ecol Prog Ser 372, 67-75.

Wild, C., Naumann, M., Niggl, W., Haas, A., 2010. Carbohydrate composition of mucus released by scleractinian warm- and cold-water reef corals. Aquat. Biol. 10, 41-45.

Yakimov, M.M., Cappello, S., Crisafi, E., Tursi, A., Savini, A., Corselli, C., Scarfi, S., Giuliano, L., 2006. Phylogenetic survey of metabolically active microbial communities associated with the deep-sea coral Lophelia pertusa from the Apulian plateau, Central Mediterranean Sea. Deep Sea Res. Part I Oceanogr. Res. Pap. 53, 62-75. doi:10.1016/j.dsr.2005.07.005

\section{Acknowledgments}

This project was carried out under the research program of the chair 'Biodiversity, Extreme environment and global change' (Fondation TOTAL and UPMC) and the joint support obtained from CNRS for the project PEPS_INEE 'CREMANT'. PEG was 
supported by the Agence Nationale de la Recherche (ANR) project MICADO (ANR11JSV7-003-01). We are grateful of the exceptional support provided by the captain, the crew RV 'Minibex' (COMEX) for their assistance in fieldwork. We also thank Ronan Becheler for acquiring the data on the genotyping of host species. The manuscript has been language-edited by NPG language editing services. Comments made by two anonymous reviewers and the editor are kindly acknowledged.

\section{Author contribution}

A.L.M., F.L. and P.E.G. designed research; A.L.M., D.K., M.B. and S.A.H. performed research; A.L.M., D.K. and P.E.G. analyzed data; and A.L.M., D.K., F.L., S.A.H., N.L.B., and P.E.G. wrote the paper.

\section{Additional Information}

The authors declare no conflict of interest.

Data deposition: The data reported in this paper have been deposited in the NCBI database (accession no. SRP064006). 


\section{Figure legends}

Figure 1. (A) Geographical location of the sampling site. The bathymetry was prepared using the GeoMapApp free software (www.geomapapp.org). (B) Coral colonies in the Lacaze Duthiers canyon and the arm of the ROV close to the sample (C) UPMC LECOB / Chaire Fondation TOTAL). (C) Distribution of the colonies collected of the two species in the Lacaze Duthiers Canyon and (D) Sample of one colony with basal and apical polyps (C F. Lartaud, LECOB).

Figure 2. Dendrogram based on the Bray-Curtis diversity index showing the similarity between the bacterial community composition of Madrepora oculata and Lophelia pertusa in duplicates (apex and basal polyps in A and B, respectively) sampled in November 2010 (bold) and May-2011. The orange L. pertusa colony is indicated by "o".

Figure 3. Bacterial community composition of Madrepora oculata (M) and Lophelia pertusa (L) sampled in November-2010 and May-2011. The composition is based on average values $>5 \%$ over all the duplicates of all the CWC. The orange $L$. pertusa colony was indicated by "o".

Figure 4. Association network of the cold-water scleractinian corals bacterial communities in which nodes correspond to the OTUs and edges correspond to the relationships calculated with the MINE statistics. The node size is proportional to the number of sequences contained in an OTU and the edge thickness to the weight of the relationship. Previous identifications were indicated by color [associated 
with cnidarians (grey), in deep (blue) and shallow (light blue) marine environments, associated with fishes (red) and in terrestrial environment (brown)].

Figure 5. Frequencies of the bacterial OTUs in Madrepora oculata and Lophelia pertusa individuals in November-2010 and May-2011. The OTUs were classified by their previous identification [associated with cnidarians (light gray), in deep (dark grey) and shallow (white) marine environments, associated with fishes (squared) and in terrestrial environments (black circle)]. The node size is proportional to the number of sequences contained in an OTU. The orange L. pertusa colony was indicated by "o".

Figure 6. Maximum likelihood tree representing the relevant OTUs and their best matching sequences specific to Madrepora oculata (M), Lophelia pertusa $(\mathrm{L})$ and unspecific sequences (LM). Bootstrap values higher than 50\% and the EMBL accession number are specified. High microbial abundance sequences are in red. 


\section{Table legend}

Table 1. Shannon (H') and dominance (D) indices and proportion of species-specific bacterial sequences and OTUs for each sample. Indices, proportion and OTUs numbers were calculated for each duplicate. Orange Lophelia pertusa was indicated y "o".

\begin{tabular}{|c|c|c|c|c|c|c|c|c|c|}
\hline Species & $\begin{array}{c}\text { Sampling } \\
\text { date }\end{array}$ & Site & Sample & $\begin{array}{l}\text { Sequences } \\
\text { total }\end{array}$ & $\begin{array}{c}\text { Species-specific } \\
\text { OTUs }\end{array}$ & $\begin{array}{l}\text { Species-specific } \\
\text { sequences }\end{array}$ & $\begin{array}{l}\text { OTUs } \\
\text { total }\end{array}$ & $\mathrm{H}^{\prime}$ & D \\
\hline \multirow[t]{8}{*}{ M. oculata } & Nov-10 & AZC3 & M1-A & 1899 & $1(11.1)$ & $1(0.1)$ & 2 & 0.0 & 1.0 \\
\hline & & & M1-B & 2488 & $3(33.3)$ & $37(1.5)$ & 8 & 0.3 & 0.9 \\
\hline & & A & M2-A & 2907 & $4(44.4)$ & 599 (20.6) & 15 & 1.1 & 0.5 \\
\hline & & & M2-B & 2639 & $5(55.6)$ & 337 (12.8) & 18 & 1.3 & 0.5 \\
\hline & May-11 & & M3-A & 2572 & $4(44.4)$ & 661 (25.7) & 8 & 1.3 & 0.4 \\
\hline & & & M3-B & 5746 & $4(44.4)$ & $99(1.7)$ & 5 & 0.2 & 0.9 \\
\hline & & & M4-A & 5773 & 7 (77.8) & $2257(39.1)$ & 10 & 1.4 & 0.4 \\
\hline & & & M4-B & 13500 & $6(66.7)$ & 1706 (12.6) & 10 & 0.6 & 0.7 \\
\hline \multirow[t]{9}{*}{ L. pertusa } & Nov-10 & AZC3 & L1-A & 4510 & 5 (11.1) & $486(10.8)$ & 8 & 0.8 & 0.6 \\
\hline & & & L1-B & 2821 & $1(2.2)$ & $30(1.1)$ & 4 & 0.4 & 0.8 \\
\hline & & A & L2-A & 992 & 8 (17.8) & $124(12.5)$ & 24 & 2.6 & 0.1 \\
\hline & & & & 5277 & $6(13.3)$ & $243(4.6)$ & 19 & 2.1 & 0.2 \\
\hline & May-11 & & Lo3-A & 1222 & $4(8.9)$ & $257(21.0)$ & 7 & 0.6 & 0.6 \\
\hline & & & Lo3-B & 2445 & $8(17.8)$ & $897(36.7)$ & 10 & 1.1 & 0.4 \\
\hline & & & L4-A & 446 & $4(8.9)$ & 78 (17.5) & 5 & 0.6 & 0.7 \\
\hline & & & L5-A & 1440 & $12(26.7)$ & $526(36.5)$ & 20 & 2.5 & 0.1 \\
\hline & & & L5-B & 3511 & $19(42.2)$ & 1587 (45.2) & 28 & 2.7 & 0.1 \\
\hline
\end{tabular}




\section{Highlights :}

-We examine the bacterial communities of two reef-building cold-water coral species from Mediterranean Sea

- The 16S rRNA sequencing revealed host-specific patterns of bacterial communities both in terms of community composition and diversity

- Our results highlight distinct host/microbes association strategies for these two closely related Scleractinians sharing the same habitat, suggesting distinct sensitivity to environmental change. 

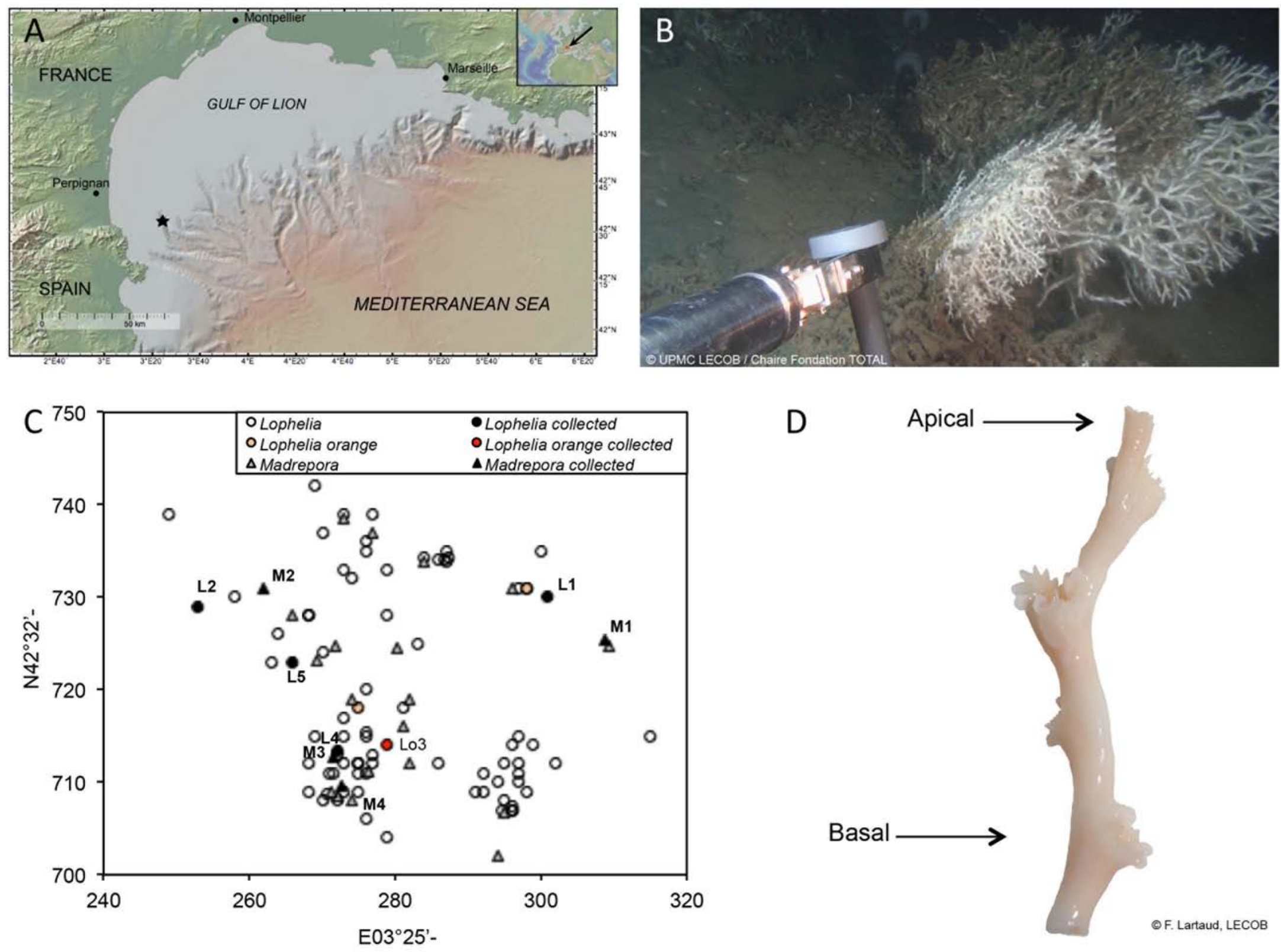


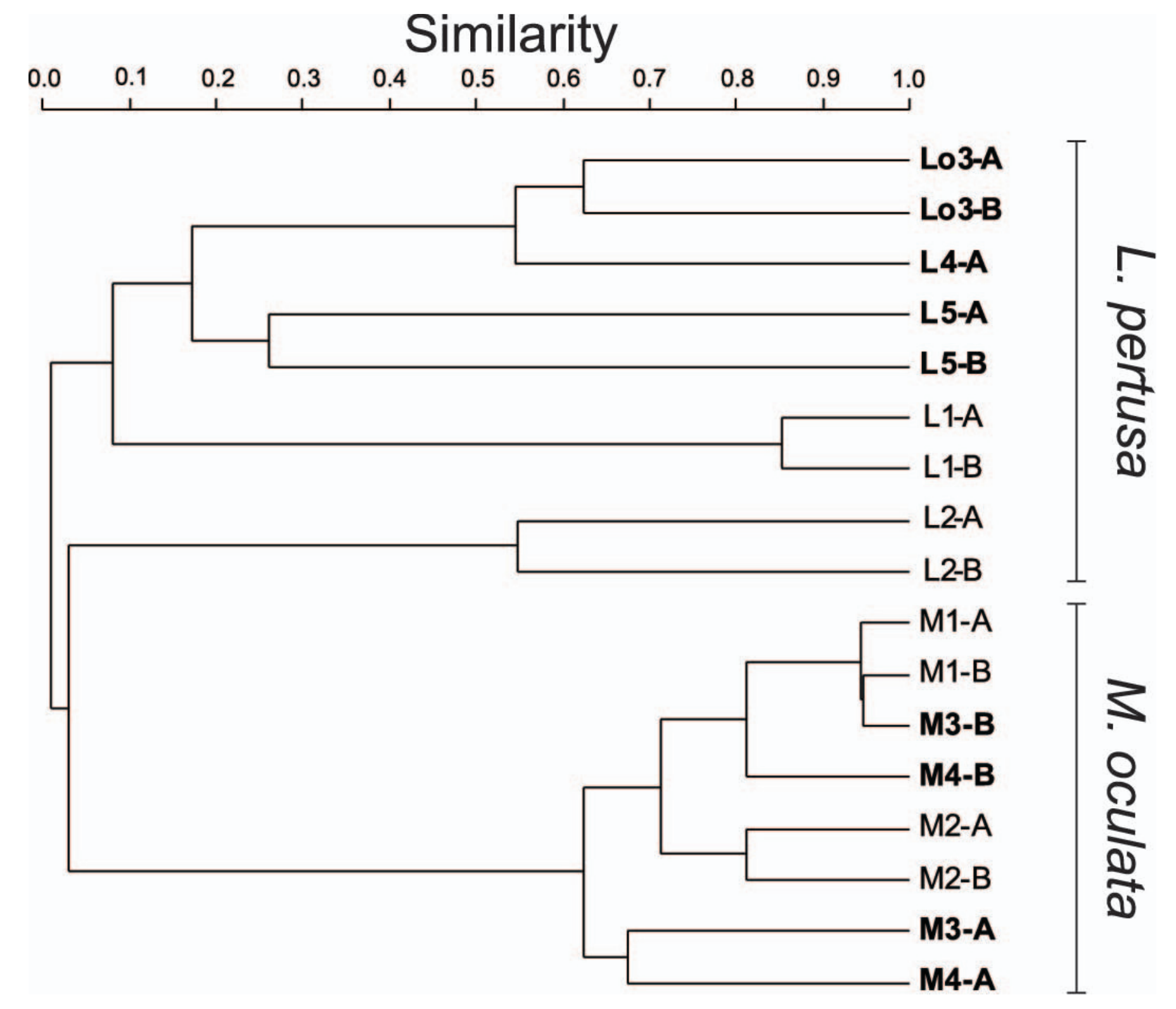




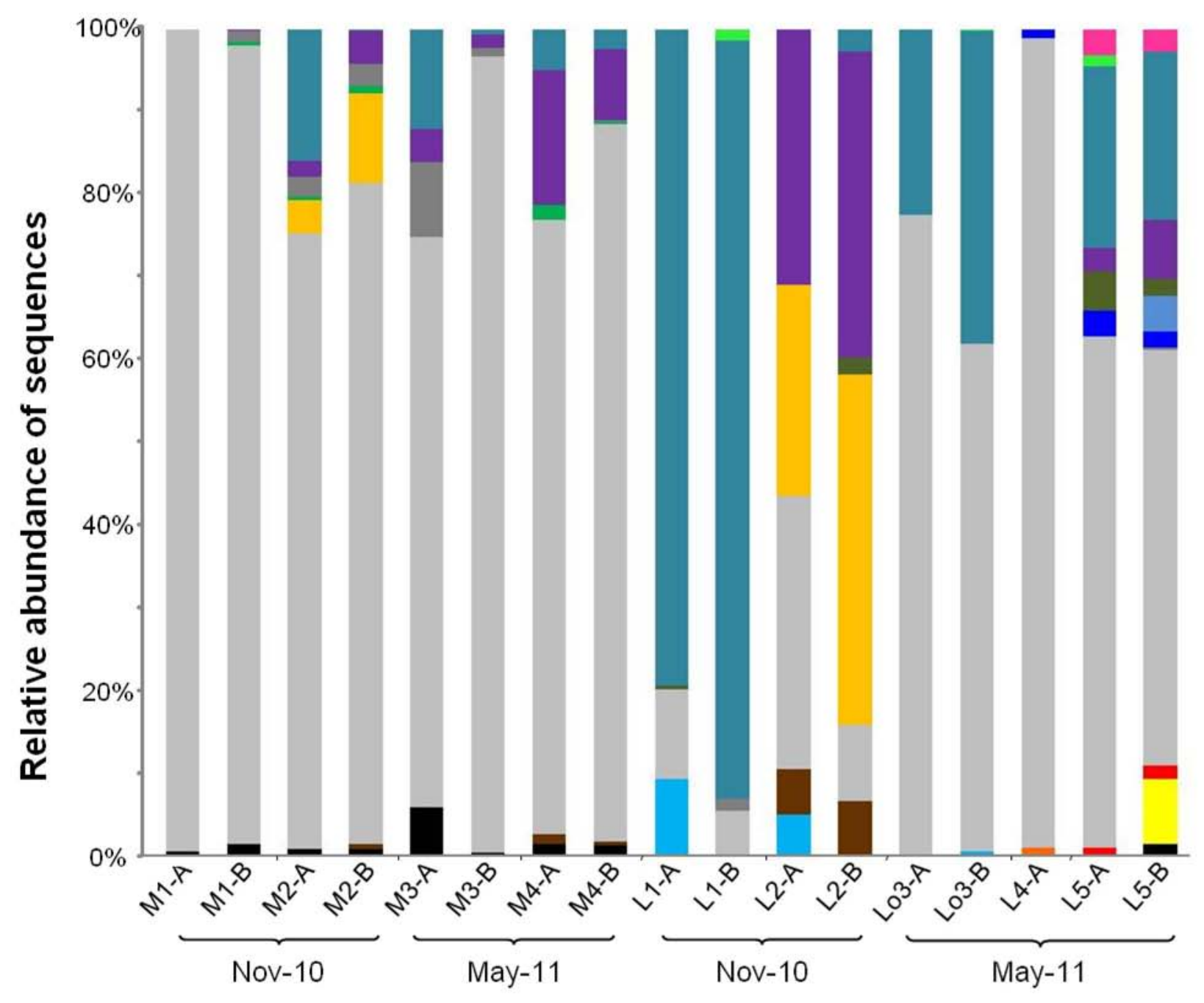

- Acidobacteria

- Actinobacteridae

- Alphaproteobacteria

- Bacteroidetes

- Betaproteobacteria

n Chloroflexi

- Deltaproteobacteria

- Epsilonproteobacteria

airmicutes

Fusobacteria

nammaproteobacteria

- Lentisphaerae

Nitrospirae

Planctomycetes

- Spirochaetes

nulfuricurvaceae

- Unclassified 

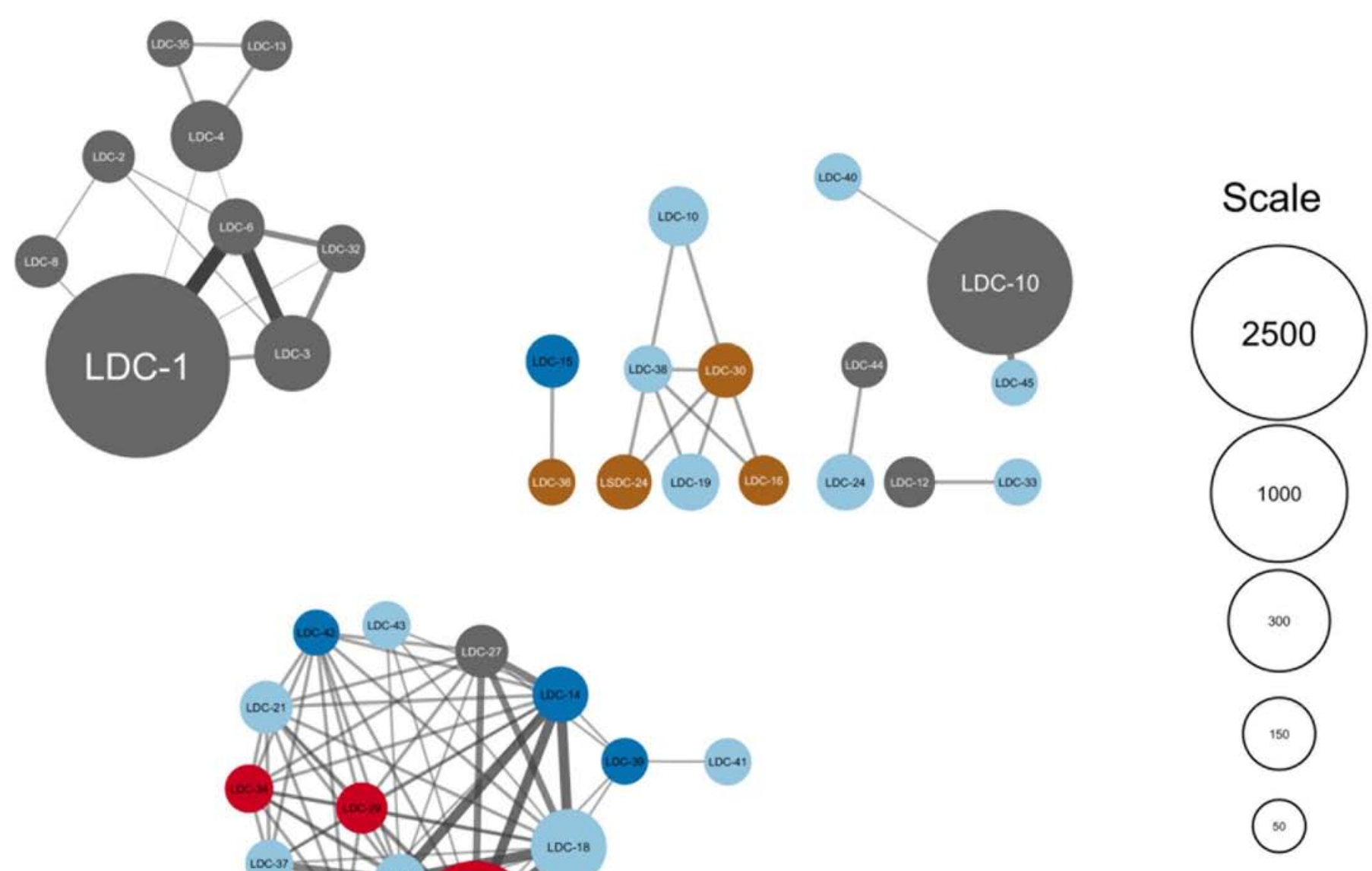


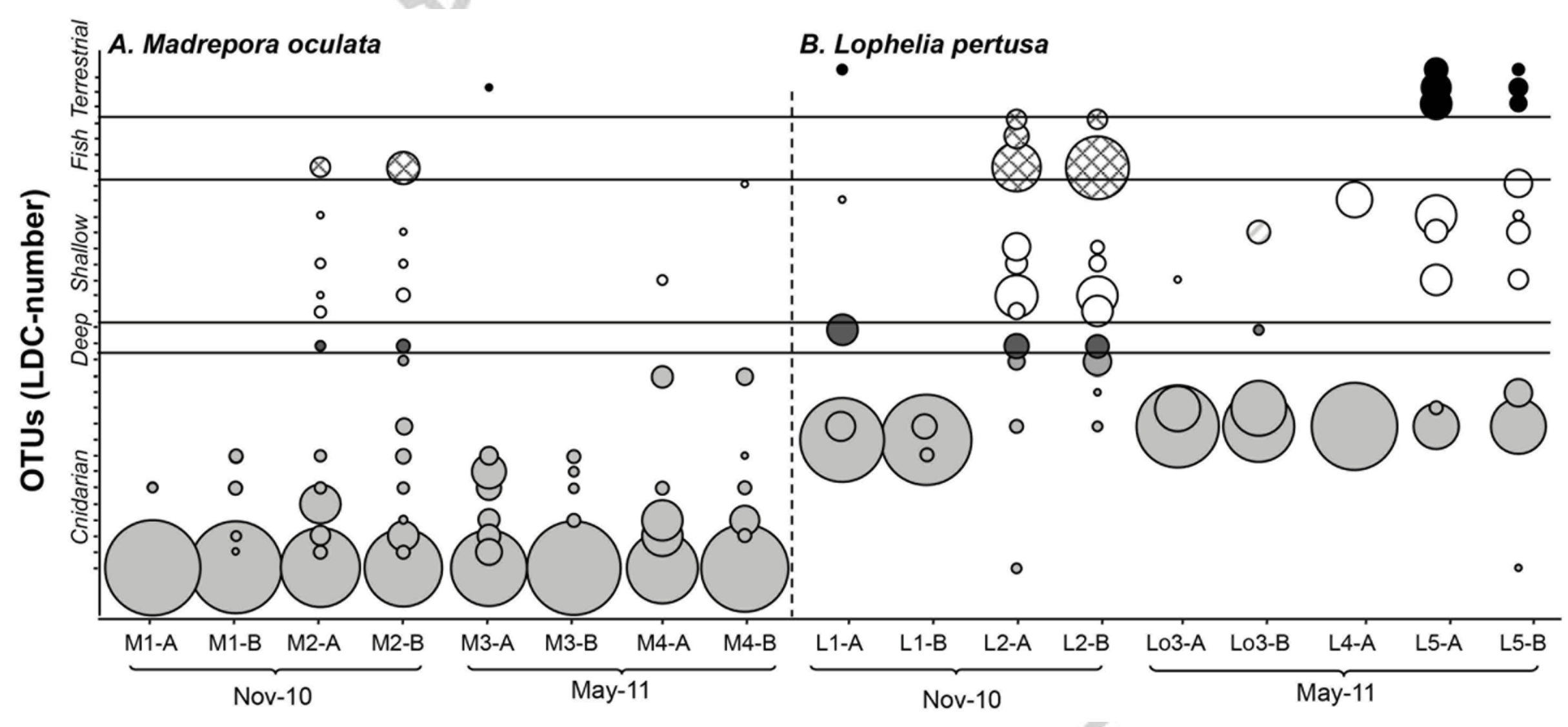




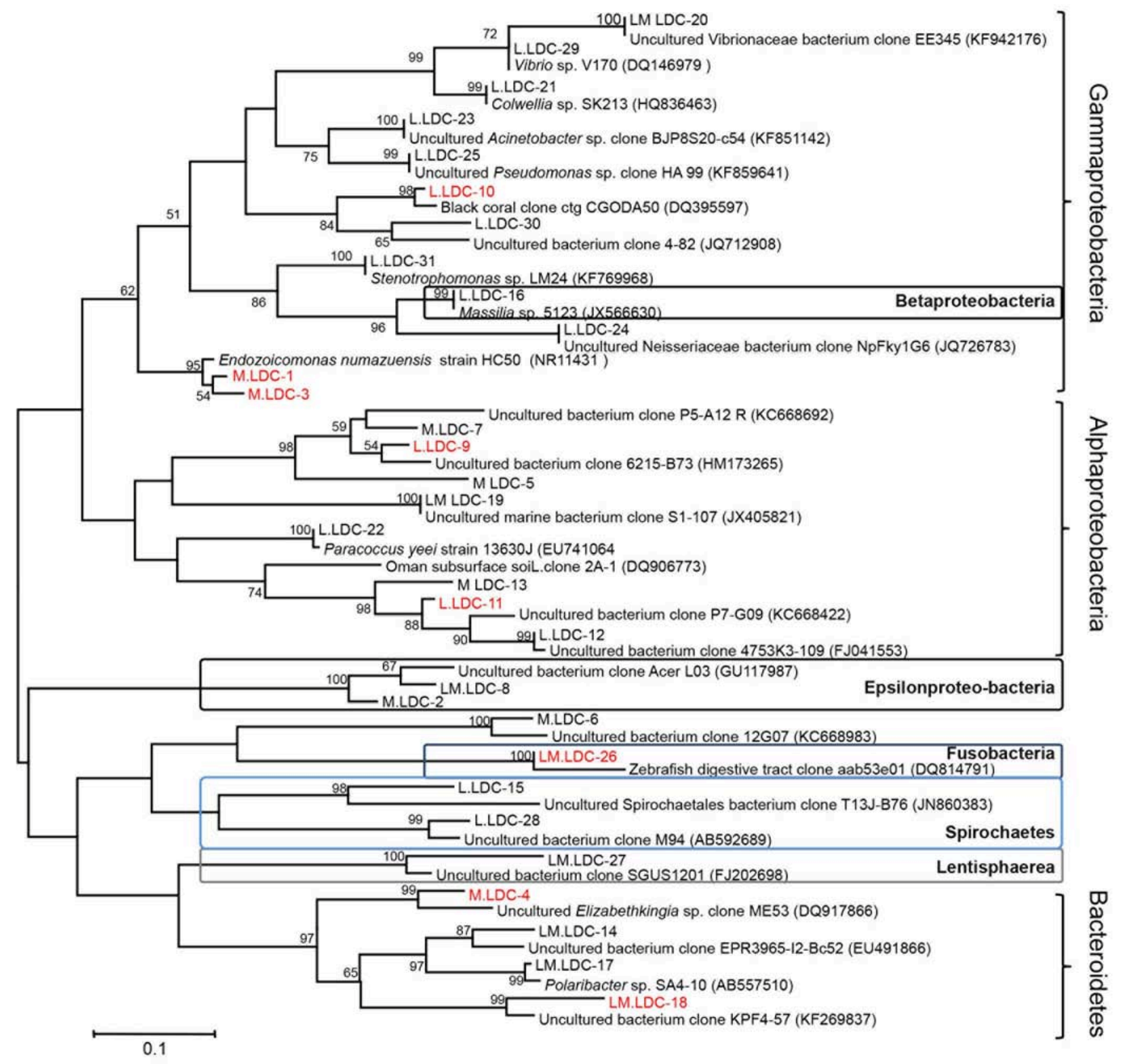


Table S1. Nearest relatives with their previous association for each of the OTUs presented at proportion higher than 5\% in all the dataset, specific to Madrepora ocululata (M), to Lophelia pertusa (L) or present in the both CWC (LM).

\begin{tabular}{|c|c|c|c|c|c|}
\hline OTU n ${ }^{\circ}$ & CWC Host & Nearest relative, Genbank accession number & Homology $(\%)$ & Taxa & Associated to \\
\hline L_LDC_9 & $\mathrm{L}$ & Uncultured bacterium clone $6215-\mathrm{B} 73, \mathrm{HM} 173265$ & 96 & Alphaproteobacteria & Cnidarian \\
\hline L_LDC_11 & $\mathrm{L}$ & Uncultured bacterium clone P7-G09, KC668422 & 93 & Alphaproteobacteria & Cnidarian \\
\hline M_LDC_5 & M & Uncultured bacterium clone P5-A12_R, KC668692 & 83 & Alphaproteobacteria & Cnidarian \\
\hline M_LDC_7 & $\mathrm{M}$ & Uncultured bacterium clone 6215-B73, HM173265 & 97 & Alphaproteobacteria & Cnidarian \\
\hline M_LDC_13 & M & Uncultured bacterium clone P7-G09, KC668422 & 87 & Alphaproteobacteria & Cnidarian \\
\hline L_LDC_22 & $\mathrm{L}$ & Paracoccus yeei strain 13630J, EU741064 & 100 & Alphaproteobacteria & Shallow marine \\
\hline L_LDC_12 & $\mathrm{L}$ & Uncultured bacterium clone 4753K3-109, FJ041553 & 99 & Alphaproteobacteria & Cnidarian \\
\hline LM_LDC_19 & LM & Uncultured marine bacterium clone S1-107, JX405821 & 100 & Alphaproteobacteria & Shallow marine \\
\hline M_LDC_4 & $\mathrm{M}$ & Uncultured Elizabethkingia sp. clone ME53, DQ917866 & 93 & Bacteroidetes & Cnidarian \\
\hline LM_LDC_18 & LM & Uncultured bacterium clone KPF4-57, KF269837 & 90 & Bacteroidetes & Shallow marine \\
\hline LM_LDC_17 & LM & Polaribacter sp.SA4-10 gene, AB557510 & 98 & Bacteroidetes & Shallow marine \\
\hline LM_LDC_14 & LM & Uncultured bacterium clone EPR3965-I2-Bc52, EU491866 & 93 & Bacteroidetes & Deep marine \\
\hline L_LDC_16 & $\mathrm{L}$ & Massilia sp. 5123, JX566630 & 100 & Betaproteobacteria & Terrestrian \\
\hline LM_LDC_8 & LM & Uncultured bacterium clone Acer_L03, GU117987 & 94 & Epsilonproteobacteria & Cnidarian \\
\hline M_L̄DC__̄ & M & Uncultured bacterium clone Acer_L03, GU117987 & 91 & Epsilonproteobacteria & Cnidarian \\
\hline LM_LDC__26 & LM & Zebrafish digestive tract clone aab53e01, DQ814791 & 97 & Fusobacteria & Fish \\
\hline M_LDC_- & M & Endozoicomonas numazuensis strain HC50, NR11431 & 96 & Gammaproteobacteria & Cnidarian \\
\hline L_LDC_10 & $\mathrm{L}$ & Black coral clone ctg_CGODA50, DQ395597 & 98 & Gammaproteobacteria & Cnidarian \\
\hline M_LDC_3 & M & Endozoicomonas numazuensis strain HC50, NR11431 & 95 & Gammaproteobacteria & Cnidarian \\
\hline L_LDC_25 & $\mathrm{L}$ & Uncultured Pseudomonas sp. clone HA_99, KF859641 & 100 & Gammaproteobacteria & Shallow marine \\
\hline L_LDC_31 & $\mathrm{L}$ & Stenotrophomonas sp. LM24, KF769968 & 100 & Gammaproteobacteria & Terrestrian \\
\hline L_LDC_30 & $\mathrm{L}$ & Uncultured bacterium clone 4-82, JQ712908 & 94 & Gammaproteobacteria & Terrestrian \\
\hline L_LDC_29 & $\mathrm{L}$ & Vibrio sp. V170, DQ146979 & 100 & Gammaproteobacteria & Fish \\
\hline L_LDC_23 & $\mathrm{L}$ & Uncultured Acinetobacter sp. clone BJP8S20-c54, KF851142 & 100 & Gammaproteobacteria & Shallow marine \\
\hline L_LDC_24 & $\mathrm{L}$ & Uncultured Neisseriaceae bacterium clone NpFky1G6, JQ726783 & 100 & Gammaproteobacteria & Shallow marine \\
\hline LM_LDC_20 & LM & Uncultured Vibrionaceae bacterium clone EE345, KF942176 & 100 & Gammaproteobacteria & Shallow marine \\
\hline L_LDC_21 & $\mathrm{L}$ & Colwellia sp. SK213, HQ836463 & 100 & Gammaproteobacteria & Shallow marine \\
\hline LM_LDC_27 & LM & Uncultured bacterium clone SGUS1201, FJ202698 & 100 & Lentisphaerae & Cnidarian \\
\hline L_LDC_15 & $\mathrm{L}$ & Uncultured Spirochaetales bacterium clone T13J-B76, JN860383 & 83 & Spirochaetes & Deep marine \\
\hline L_LDC_28 & $\mathrm{L}$ & Uncultured bacterium clone M94, AB592689 & 95 & Spirochaetes & Fish \\
\hline M_LDC_6 & M & Uncultured bacterium clone 12G07, KC668983 & 93 & Unclassified & Cnidarian \\
\hline
\end{tabular}

